\section{VENOUS THROMBOSIS - THE INTERACTION OF GENES AND ENVIRONMENT}

$\mathrm{V}$ ENOUS thrombosis is the obstruction of the circulation by clots that have been formed locally in the veins or have been released from a thrombus elsewhere. The usual sites of thrombus formation are the superficial and deep veins of the legs, but it also may occur in veins in the brain, retina, liver, and mesentery.

An important question is why thrombosis develops in a given person at a specific site at a particular age and time. Probably the formation and growth of a thrombus are caused by local activation of the coagulation system, combined with a disturbance in the balance between coagulation and fibrinolytic reactions favoring clot formation. An increased risk of venous thrombosis can last throughout life because of the presence of mutations in genes coding for hemostatic or fibrinolytic proteins, but the increase in risk may also be of limited duration - that is, due to acquired or environmental factors.

The involvement of genetic factors was recognized in earlier reports on familial clustering of venous thrombotic events (familial thrombophilia); 20 to 30 percent of patients with thrombosis report having at least one relative with thrombosis. On the other hand, clinical studies have revealed that acquired conditions such as trauma, surgery, immobilization, pregnancy, the puerperium, and use of oral contraceptives are important risk factors for venous thrombosis. Detailed information on the identity of these risk factors and the extent of their interaction is needed to establish a policy for individualized treatment and prevention.

In this issue of the Journal, Martinelli et al. ${ }^{1}$ report on the interaction of two recently identified, common prothrombotic mutations and the use of oral contraceptives in a study of the risk of cerebralvein thrombosis. Because of the high prevalence of these mutations in the general population, only 40 patients werc required for the authors to draw meaningful conclusions from the study.

What are these mutations? The first is a mutation in the gene coding for coagulation factor V. A transtion (guanine to adenine) at nucleotide 1691 (G1691A) in exor 10 of the factor $\mathrm{V}$ gene results in the replacement of arginine at position 506 by glutamine (factor V Q506, factor V Leiden). ${ }^{2}$ Factor $\mathrm{V}$ circulates in the blood as an inactive procofactor: it can be activated by thrombin, resulting in the formation of a two-chain molecule (factor Va) that serves as a cofactor of factor $\mathrm{Xa}$ in the conversion of prothrombin into thrombin. Inactivation of factor Va occurs through selective proteolytic cleavages in its heavy chain at $\operatorname{Arg} 306, \operatorname{Arg} 506$, and $\operatorname{Arg} 679$.
The responsible enzyme is activated protein C. Activated factor $\mathrm{V}$ Leiden, with a glutamine instead of an arginine at position 506, is not cleaved by activated protein $\mathrm{C}$ at this position and is therefore inactivated more slowly. This is the molecular basis of the laboratory phenotype of resistance to activated protein $C$, first reported by Dahlbäck et al. ${ }^{3}$

The proportion of carriers of factor $\mathrm{V}$ Leiden in the white population varies from 2 percent to 15 percent. The mutation is extremely rare in nonwhites, and there is strong evidence that all factor $\mathrm{V}$ Leiden alleles originate from a common ancestor. ${ }^{4}$ Heterozygous carriers have a risk of deep-vein thrombosis that is 7 times as high as that in the general population; for homozygous carriers, the risk is 80 times as high. 5

The second prothrombotic mutation involves a guanine-to-adenine transition at nucleotide 20210 of the gene encoding prothrombin, the inactive precursor of thrombin, which is the end product of the coagulation cascade. ${ }^{6}$ The importance of this transition is not yet known, but several investigators have reported that heterozygous carriers have 30 percent higher plasma prothrombin levels than noncarriers. Heterozygous carriers are known to have a risk of deep-vein thrombosis that is three to six times that in the general population. Again the abnormality is rare in nonwhite populations. In whites the reported prevalence of carrier status varies from 0.7 percent to 4 percent.

The finding that the G1691A mutation in the factor $\mathrm{V}$ gene and the G20210A mutation in the prothrombin gene are common, strong risk factors for venous thrombosis in the legs raised the possibility that these mutations might also be associated with other forms of venous thrombosis. ${ }^{8}$ It also raised the question whether there may be an interaction between genetic and environmental risk factors for venous thrombosis. ${ }^{9}$ Furthermore, the role of thrombin formation in other complex diseases, such as myocardial infarction, stroke, eclampsia and preeclampsia, and diabetes, became a focus of research interest.

It is in this context that we have to consider the data reported by Martinelli et al. ${ }^{1}$ from their study of the roles of prothrombotic mutations and the use of oral contraceptives in the development of idiopathic cerebral-vein thrombosis, a rare form of venous thrombosis. They compared the frequency of the mutations G1691A and G20210A and the use of oral contraceptives among 40 unrelated patients who had a confirmed diagnosis of cerebral-vein thrombosis with that among 120 healthy controls. They made two important observations. First, the prothrombin-gene mutation G20210A is an important risk factor for cerebral-vein thrombosis. This supports previous findings by the same authors and others regarding factor $\mathrm{V}$ Leiden as a risk factor for 
cerebral-vein thrombosis. ${ }^{1012}$ Interestingly, the frequency of the two mutations was very similar among patients with cerebral-vein thrombosis and among voung patients with deep-vein thrombosis in the legs, pointing to a similar role of these mutations in the development of two different presentations of the same disease.

The second observation concerns the contribution of oral-contraceptive use to the risk of cerebralvein thrombosis. The use of oral contraceptives appeared to be a strong risk factor for cerebral-vein thrombosis (odds ratio, 22.1; 95 percent confidence interval, 5.9 to 84.2 ), which is in agreement with the results of an earlier study in which a relative risk of approximately 13 (95 percent confidence interval, 5 to 37 ) was reported for oral-contraceptive users. ${ }^{13}$ What is particularly interesting is that for women who were, both carriers of the G20210A prothrombin-gene allele and current users of oral contraceptwes, the risk of cerebral-vein thrombosis (odds ratio, 149.3) far exceeded the sum of the separate risks associated with these two factors. This again points to an interaction between a prothrombotic mutation and the use of oral contraceptives and extends the findings of previous studies that have documented an interaction between factor $\mathrm{V}$ Lciden and oral-contraceptive use in causing deep-vein thrombosis in the legs and cerebral-vein thrombosis. ${ }^{13,14}$ At a molecular level, this interaction is not well understood. Oral-contraceptive use results in changes in the concentrations of many hemostatic and fibrinolytic components of the blood and may add in multiple ways to the disturbance in the hemostatic balance that is introduced by a prothrombotic mutation.

Martmelli et al. further report that 78 percent of all their patients with cerebral-vein thrombosis were women and that, after the exclusion of women who were pregnant or postmenopausal at the time of the event, 96 percent used oral contraceptives; 37 percent were both carriers of a prothrombotic mutation and users of oral contraceptives. These figures clearly differ from those in patients with deep-vem thrombosis in the legs: about 60 percent of these patients are women, of whom 40 percent use oral contraceptives, and 10 percent are both carriers of a prothrombotic mutation and current users of oral contraceptives. ${ }^{1+}$ So we have to consider seriously the possibility, previously discussed by de Bruijn et al. ${ }^{13}$ that the introduction of oral contraceptives has contributed to the incidence of cerebral-vein thrombosis. This may have occurred particularly in women from famules with thrombophilia.

Finally, we still do not know why venous thrombosis develops in the brain in some patients and in the leg in others. The very voung age of the patients with cerebral-vein thrombosis at the time of the crent (median, 31 vears) indicates that in these pa- tients, there must be additional risk factors that are still unknown..$^{15}$

R.M. Bertina, Ph.D.

F.R. ROSENDAAL, M.D.

Lesden Unversity Medical Center

2333 ZA Leiden, the Netherlands

\section{REFERENCES}

1. Martuncliı I, Sacchı E, Landı G, Taolı E, Duca F, Mannucca PM Hagh rish of cerebral vem thrombosis in carriers of a prothrombin-gene mutation and in uscrs of oral contraceptres N Engl J Med 1998,338 1793-7.

2. Bertina RM, Koeleman BPC, Koster $T$, et al Mutation in blood coagulation tactor $V$ associated with resistance to activated proten $C$. Nature $1994,36964-7$

3. Dahiback B, Carlsson M, Sicnsson PJ Familial thrombophilia due to a prevousl unrecognized mechanism characterized by poor anticoagulant response to actinated protem $C$ prediction of a cofactor to activated protcin C. Proc Natl Acad Su U S A 1993,90 1004-8

4. Zuelun A, Griffin IH, Xu X, et al A single genetu ortgin for a common Caucasıan risk factor tor venous thrombosis Blood 1997,89 397-402.

5. Rosendaal FR, Koster T, Vandenbroucke JP, Reitsma PH High risk of

thrombosis in paticnts homozvgous for factor $V$ Lerden (activated protein C resistance) Blood 1995,85 1504-8

6. Poort SR, Rosendaal FR, Ritsma PH, Bertma RM A common genetic iariation in the 3 '-untranslated regoon of the prothrombin gene is assoc1ated with elevated plasma prothrombin levels and an increase in venous thrombosis Blood 1996,88 3698-703

7. Rosendaal FR, Doggen CIM, Zivelın A, et al. Geographe distribution of the $20210 \mathrm{G}$ to A prothrombin variant Thromb Haemost 1998,79 7068

8. Desmaras S, de Moerloose P, Reber G, Mnazıo P, Perrıer A,

Bounameaus $H$ Resistance to activated protem $C$ in an unselected population of patients with pulmonary embolism Lancet 1996,347 1374-5

9. Rosendaal FR Risk tactors tor ienous thrombosis prevalence, risk, and interaction Semun Hematol 1997,34 171-87

10. Martincli I, Land, G, Meratı G, Cella R, Tosetto A, Mannuce PM Factor $V$ gene mutation is a usk factor for cerebral venous thrombosis Thromb Hacmost 1996,753934

11. Deschens MA, Conard I, Horellou MH, et al Coagulation studies, factor V Leiden, and anticardioliom antibodics in 40 cases of cerebral ienous thrombosis Stroke 1996,27 1724-30

12. Zuber $M$, Toulon P, Marnet L, Mas IL Factor V Leden mutation un cerebral venous thrombosts Strohe 1996,27 1721-3

13. de Bruun SF, Stam J, Koopman MIM, Vandenbroucke JP Case control studr of rosk of cercbral sinus thrombosis in oral contraceptre users who are carriers of hereditary prothromboth conditions BMJ 1998,316 58992

14. Vandenbrouke JP, Koster T, Briet F, Reirsma PH, Bertina RM, Rosendaal $\mathrm{HR}$ Increascd risk of venous thrombosis in oral contraceptne users who are carriers of tactor $V$ Leiden mutation Lancet 1994,344 $1453-7$

15. Lensen RP, Rosendaal FR, Koster T, et al tpparent different thrombotk tendenc $v$ in patients with tactor $V$ Leiden and protum $C$ defictencs duc to selestion of patunts Blood 1996,88 $\$ 2058$

(9)1998, Massahusetts Nedical Souter

\section{Fatal Impact - Concussion OF THE HEART}

W HEN he died on a winter evening in 1995 , Matthew Messing was only 16 years old. It happened while he was playing in a high-school icehockey game in Quincy, Massachusetts. The referee said the boy was hit squarely in the chest by an opponent during a routine body-checking maneuver. The spectators noticed nothing unusual about the 